\title{
Application of Acoustic Emission to seeded gear fault detection
}

\author{
Tim Toutountzakis, Chee Keong Tan, David Mba \\ School of Engineering, Cranfield University, Bedfordshire. MK43 0AL, UK \\ Tel: +44 (0) 1234-750 111 ext 2371, Fax: +44 (0) 1234-752376. \\ E-mail : c.k.tan@cranfield.ac.uk,d.mba@cranfield.ac.uk
}

\begin{abstract}
Acoustic Emission (AE) is gaining ground as a Non-Destructive Technique (NDT) for health diagnosis on rotating machinery. There are vast opportunities for development of the $\mathrm{AE}$ technique on various forms of rotating machinery, including gearboxes. This paper reviews some recent developments in application of AE to gear defect diagnosis. Furthermore, an experimental investigation that examines the effectiveness of AE for gear defect identification is presented. It is concluded that application of the $\mathrm{AE}$ technique to seeded gear defect detection is fraught with difficulties. In addition, the viability of the $\mathrm{AE}$ technique for gear defect detection from non-rotating components of a machine is called into question.
\end{abstract}

Keywords: Acoustic Emission, condition monitoring, gear fault diagnosis, machine health diagnosis. 


\section{Introduction}

Application of high frequency Acoustic Emission (AE) technique in condition monitoring of rotating machinery has been growing over recent years. This is particularly true for bearing defect diagnosis and seal rubbing [1-5]. The main drawback with the application of the $\mathrm{AE}$ technique is the attenuation of the signal and as such the $\mathrm{AE}$ sensor has to be close to its source. However, it is often practical to place the AE sensor on the non-rotating member of the machine, such as the bearing or gearbox casing. Therefore, the AE signal originating from the defective component will suffer severe attenuation before reaching the sensor. Typical frequencies associated with AE activity range from $20 \mathrm{kHz}$ to $1 \mathrm{MHz}$.

Whilst vibration analysis for gear fault diagnosis is well established, the application of $\mathrm{AE}$ in this field is still in its infancy. In addition, there are limited publications on application of AE to gear fault diagnosis. Siores et al [6] explored several AE analysis techniques in an attempt to correlate all possible failure modes of a gearbox during its useful life. The gearbox used for this investigation consisted of two spur gear sets of 34 and 60 teeth and 45 and 20 teeth respectively. The gears were run-in by operating the gearbox at $1200 \mathrm{rpm}$ with full load at four one-hour intervals. Failures such as shaft misalignment, tooth breakage, scuffing and a worn tooth were seeded during tests. Siores correlated the various seeded failure modes of the gearbox with the $\mathrm{AE}$ amplitude, r.m.s. standard deviation and duration. It was concluded that the AE results could be correlated to various defect conditions. 
Singh et al [8-9] performed three experiments to study the feasibility of applying AE to gear fault diagnosis. The first experiment [8] employed two different gearboxes for simulated gear pit detection. For both test set-ups, the simulated pit was introduced on the pitch line of a gear tooth using an Electrical Discharge Machining (EDM) process. An AE sensor with a resonant frequency $280 \mathrm{KHz}$ and an accelerometer for comparative purposes were employed in both test cases. It was important to note that both the accelerometer and AE sensor were placed on the gearbox casing.

The first gearbox employed was an UH1H "Generator Drive Offset Quill" with a gear ratio of 41:55 and rotational speeds of 1400 and $920 \mathrm{rpm}$. The simulated pit introduced was $1.25 \mathrm{~mm}$ in diameter and depth. It was observed that the AE amplitude increased with increased rotational speed and AE activity was observed with increased pitting. The second gearbox was a back-to-back with gear ratio 42:28 and an input speed of $1775 \mathrm{rpm}$. During this test, periodically occurring peaks were observed when natural pitting started to appear after half an hour of operation. These AE activities increased as the pitting spread over more teeth. Singh et al concluded that AE could provide earlier detection over vibration monitoring for pitting of gears, but noted it could not be applicable at extremely high speeds or for unloaded gear conditions.

For the second experiment, tooth bending tests were carried out using a single tooth bending setup. In this test, a sinusoidal load was applied at a frequency of $40 \mathrm{~Hz}$. The number of cycles and the amplitude of the AE signal were monitored and stored in real time until failure occurred. From this experiment, Singh concluded that AE could 
detect crack initiation and growth, while the accelerometer could only detect the crack growth at a later stage of the crack growth process.

The final experiment performed by Singh et al [9] involved assessment of the transmissibility of an AE signal within a gearbox. The tests were performed with different torque levels using lead pencil breaks to simulate AE activity in the gearbox. This technique is known as the Nielsen source test. Various AE transmission paths were examined. AE sensor was placed on the gear wheel to measure the initial strength of the signature and second sensor was mounted on the ball bearing pedestal to capture the transmitted signal. It was observed that greater attenuation was experienced for lighter loads though attenuation remained rather constant at the high load conditions. Singh et al concluded that the attenuation across the gearbox was an accumulation of losses across each individual interfaces within the transmission path and the optimum path of propagation will be the one with the smallest cumulative loss.

Tandon et al. [10] performed an experiment to correlate AE parameters, such as peak amplitude, ringdown count and energy with gear defect size. The experimental set-up employed a back-to-back gearbox with a gear ratio of 15:16. An AE sensor with resonant frequency of $375 \mathrm{KHz}$ and an accelerometer of natural frequency of $39 \mathrm{kHz}$ were employed for this experiment. The tests were performed at a rotational speed of $1000 \mathrm{rpm}$ under different load conditions. Simulated pits on the pitch-line with constant depth $(500 \mu \mathrm{m})$ and varying diameters from 250 to $2200 \mu \mathrm{m}$ were introduced using the spark erosion technique. Tandon et al observed that the monitored AE parameters increased with defect size (pit diameter) and load. Tandon et al also concluded that AE 
has a better detection capability over vibration since it was able to detect smaller pit sizes.

Whilst the details presented above have related to seeded defect identification some observations correlating AE activity to natural pitting have also been reported. Sentoku [7] correlated tooth surface damage such as pitting to AE activity. This experiment employed a back-to-back gearbox arrangement (25 to 31 teeth) with a pinion speed of $992 \mathrm{rpm}$. An AE sensor of resonant frequency $350 \mathrm{kHz}$ was mounted on the gear wheel. The AE signature was transmitted from the sensor to data acquisition card across a mercury slip ring. A strain gauge was mounted on the tooth root to relate the extracted AE parameters with the tooth root strain values. It is important to note that this experiment was performed under a constant oil temperature. This eliminated the effect of oil film thickness on AE activity. In this experiment, natural pitting occurred at about $1 \times 10^{6}$ cycles and it was concluded that AE amplitude and energy increased with increased pitting.

Toutountzakis et al [11] presented some interesting observations of AE activity due to misalignment and natural pitting. The test was performed on a back-to-back gearbox with a spur gear set of 49 and 65 teeth and an the AE sensor used was a resonant type placed on the pinion. A sliver contact air-cooled slip ring was employed to transmit the $\mathrm{AE}$ signal for further processing. Toutountzakis et al concluded that $\mathrm{AE}$ technique demonstrated the potential for gear fault diagnosis. 
Although the development of AE in gear diagnosis is in its infancy, the papers reviewed have illustrated the potential and viability of AE becoming a useful diagnostic tool in condition monitoring of gears. However, more detailed investigations are required to ensure this technique is robust and applicable for operational gearboxes. The purpose of this investigation was to determine an effective AE indicator for seeded gear defect detection. An experimental test-rig was employed that allowed for various sized defects to be seeded onto the test gears.

\section{Experimental set-up}

The test-rig consisted of two identical oil-bath lubricated gearboxes, connected in backto-back arrangement, see figure 1. The gears employed were made of 045M15 steel without any heat treatment. The gears (49 and 65 teeth) used had a module of $3 \mathrm{~mm}$, a pressure angle of $20^{\circ}$, and surface roughness of between 2-3 $\mu \mathrm{m}$. Each gearbox had four identical ball bearings. A simple mechanism that permitted a pair of coupling flanges to be rotated relative to each other, and locked in position, was employed to apply torque to the gears. The effect of this process was to twist the shafts and lock in the torque within the loop of the back-to-back gearbox. The effective torque loading was a combination of the static and dynamic (inertia) loading. Three sets of torque were used for the experiment: $0 \mathrm{Nm}, 55 \mathrm{Nm}$ and $110 \mathrm{Nm}$. The contact ratio of the gear was 1.77. It must be noted that the $0 \mathrm{Nm}$ condition is not literally ' $0 \mathrm{Nm}$ '. There exists a light load at this condition due to the bearing friction and losses/resistance associated with the rubber seals, gear churning and windage. If a true ' $0 \mathrm{Nm}$ ' condition was obtainable, the gear would run in a non-linear manner. An AC three-phase electrical motor (1.1 KW) 
with speed of $745 \mathrm{rpm}$ was employed to drive the gearbox. The lubricant used was an EP SAE 80W-90, GL-4 API mulit-grades gearbox oil so as to keep natural pitting and wear to minimum level during the seeded fault tests.

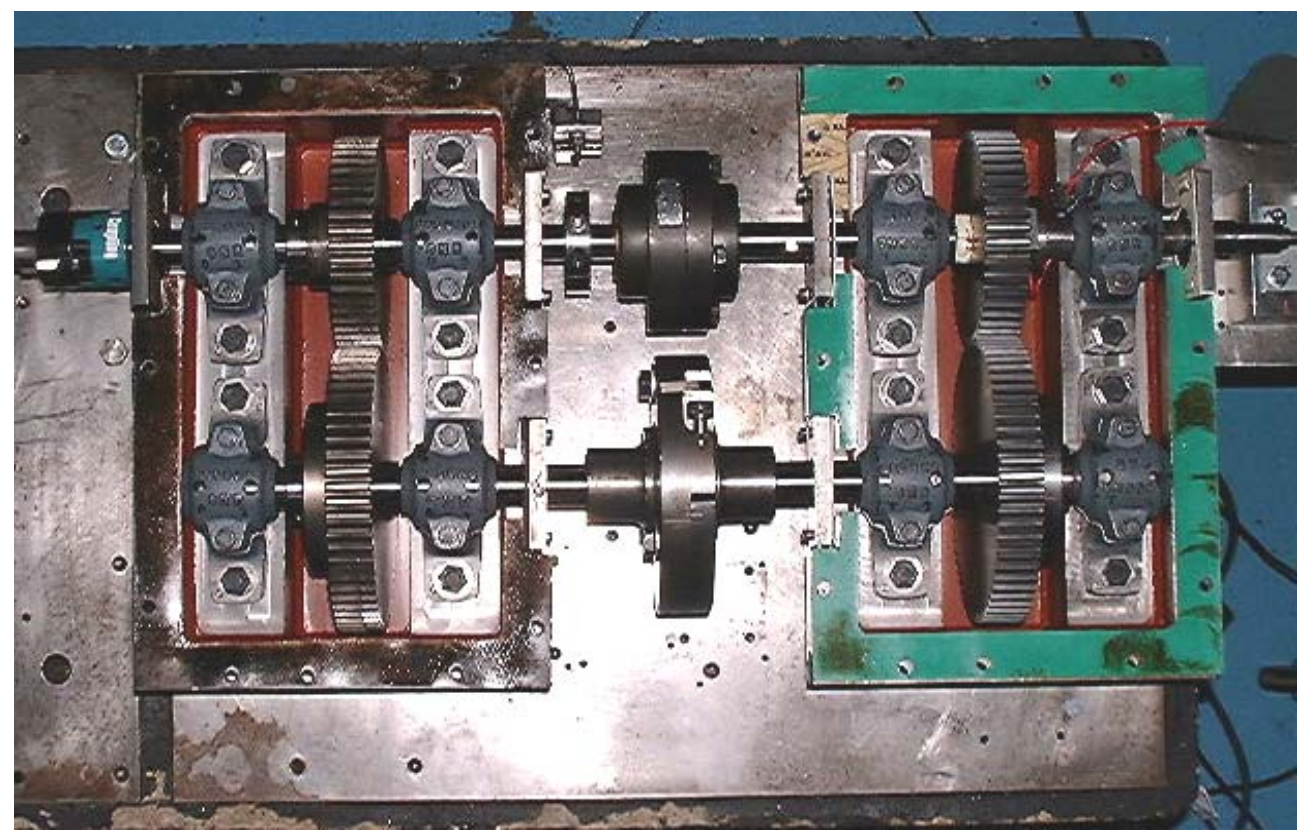

Figure 1 Test-rig gearboxes in back-to-back arrangement.

\section{Sensors and Acquisition Systems}

The AE sensors used for this experiment were broadband type sensors with a relative flat response in the region between $100 \mathrm{KHz}$ to $1 \mathrm{MHz}$ (Model: WD, 'Physical Acoustics Corporation'). One sensor was placed on the pinion (49 teeth) and the other on the bearing casing (figure 2) of the pinion shaft. The cable connecting the sensor placed on the pinion with the pre-amplifier was feed into the shaft and connected to a slip rig, see figure 3. This arrangement allowed the AE sensor to be placed as close as possible to the gear teeth. Both sensors were held in place with mechanical fixtures. A 
PH-12 slip rig manufactured by 'IDM Electronics Ltd' was employed. The slip rig used silver contacts and could accommodate up to 12 channels. The slip rig had an air intake where pressurised air was fed for cooling and cleanliness purposes at a rate of $0.014 \mathrm{~kg} / \mathrm{mm}^{2}$ (figure 3 ). The output signal from the AE sensors was pre-amplified at 40dB. The signal output from the pre-amplifier was connected (i.e. via BNC/coaxial cable) directly to a commercial data acquisition card where a sampling rate of $10 \mathrm{MHz}$ was used during the tests.

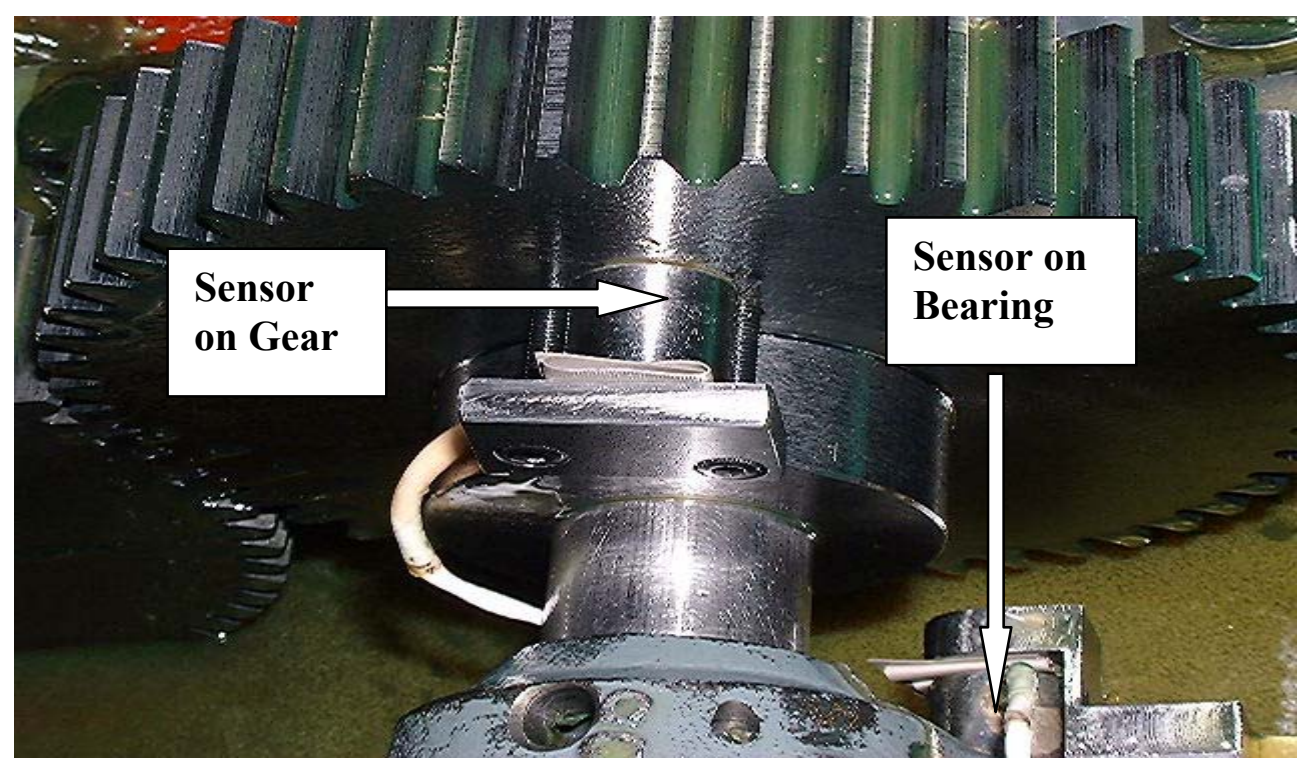

Figure 2 AE sensors located on the pinion and bearing casing. 


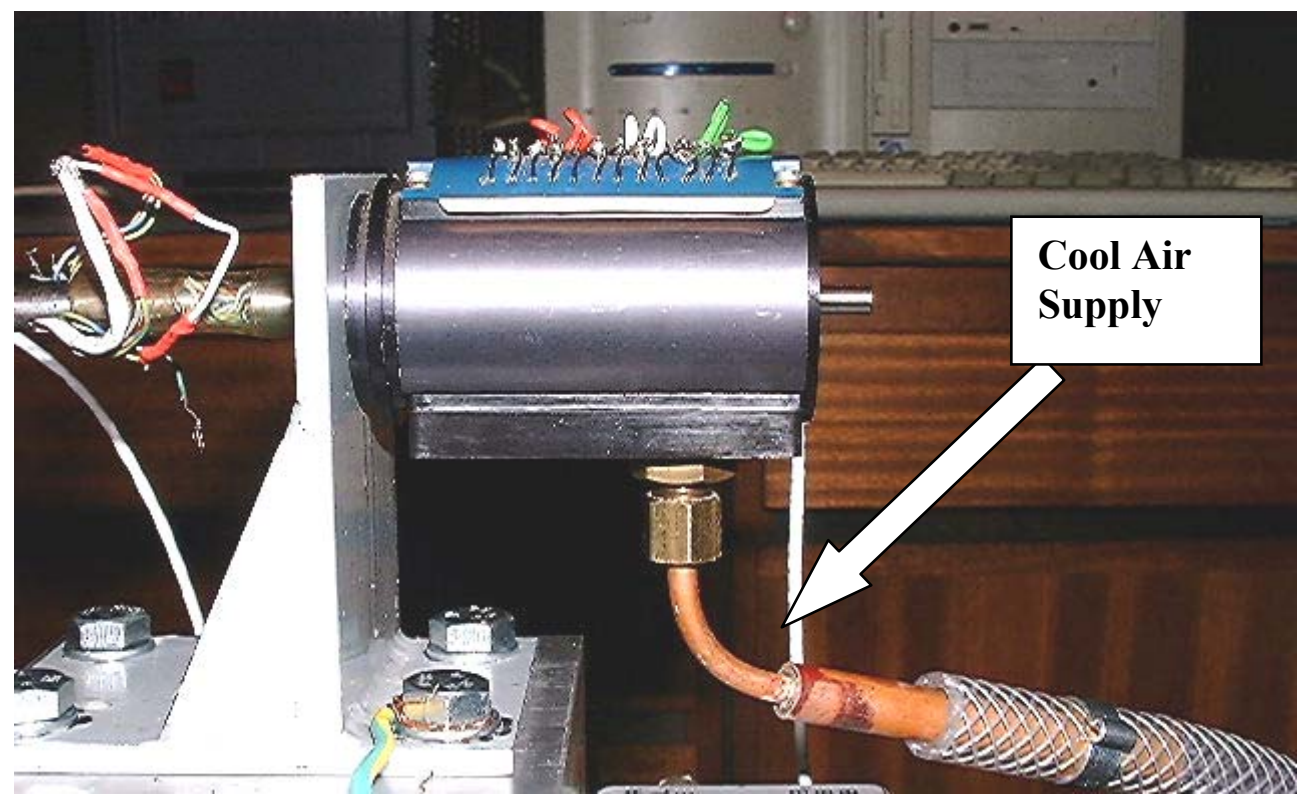

Figure $3 \quad$ Slip ring coupled with cool compressed air supply.

\section{Test Procedures}

The gearbox was run-in for more than 15 hours before the actual experiment was carried out. Prior to the start of the test, an attenuation test on the gearbox components was undertaken in order to understand the characteristics of the test-rig.

The test started with a defect free condition so that the operational background noise characteristics were observed. The gearbox was run for 30 minutes prior to acquiring AE data for the no load condition. The gearbox was then shut down to adjust to the next torque level $(55 \mathrm{Nm})$. After another 30 minutes of continuous running, the AE signal for this load condition was acquired. This procedure was repeated for the load condition of $110 \mathrm{Nm}$. 
For the seeded defect condition, a pitch-line defect of $1 \mathrm{~mm}$ in diameter (see figure 4) was introduced and $\mathrm{AE}$ data was collected by repeating the loading procedures detailed in the former paragraph. Lastly, the test was repeated for a large addendum defect (extended from the pitch-line) measuring $12 \mathrm{~mm}$ by $3 \mathrm{~mm}$ (see figure 5 ). Based on the sampling rate of $10 \mathrm{MHz}$, the acquisition time available for recording was 0.0256 seconds which represented 0.31 revolutions (16 teeth) of the pinion at $745 \mathrm{rpm}$. The seeded defects were introduced on the tooth flank of a tooth using an engraving machine. By employing a trigger mechanism, only AE data from the portion of the pinion gear wheel where the defect was located was acquired. The trigger system was set such that the defective gear tooth was at the mid point of the acquisition window (0.0256 seconds), see figure 6.

The application of AE to gear diagnostics is considered to be relatively new. Although there are many $\mathrm{AE}$ analysis techniques available, selection of a robust technique is of paramount importance if $\mathrm{AE}$ is to gain acceptability as a diagnostic tool. The $\mathrm{AE}$ parameter chosen for the gear defect diagnosis analysis was the root mean square (r.m.s), a common AE parameter usually employed for diagnosis. 


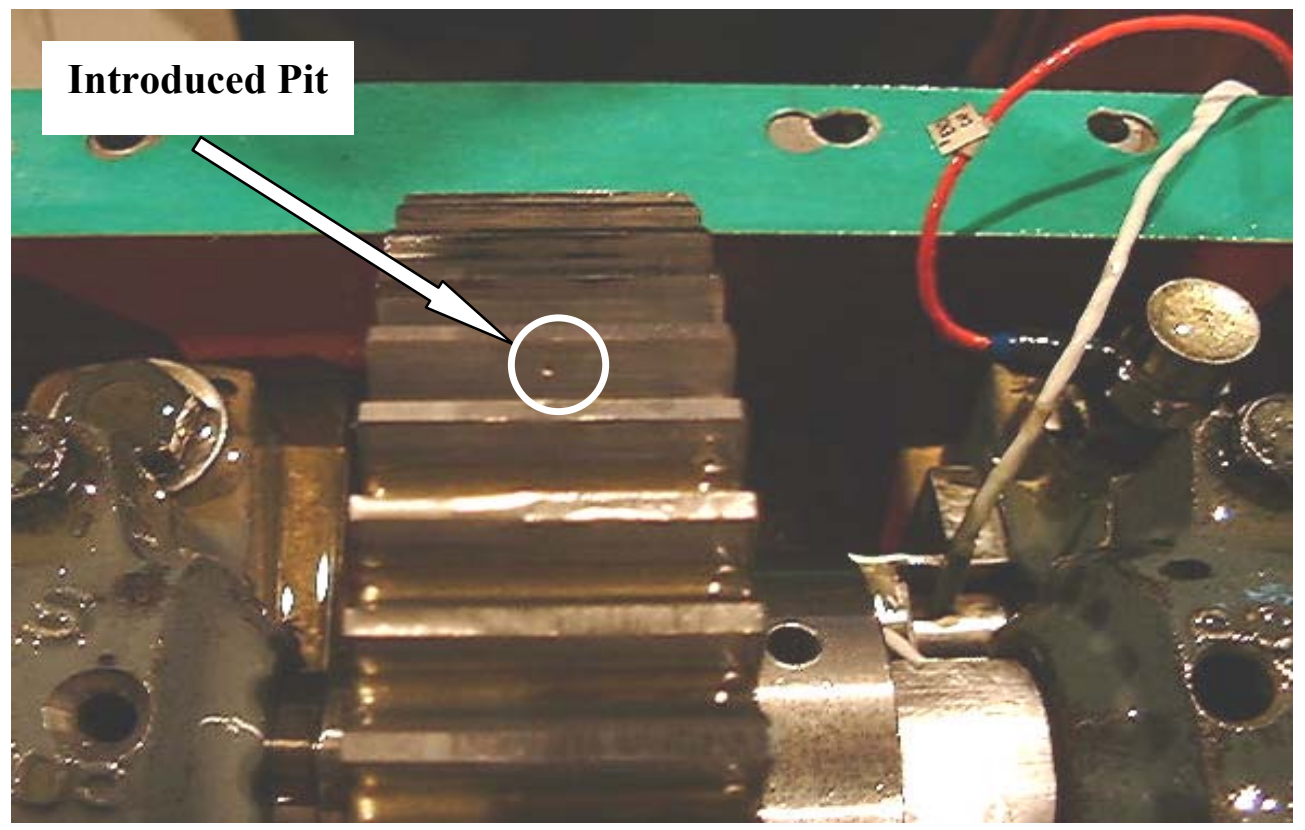

Figure 4 Seeded small pitch-line defect.

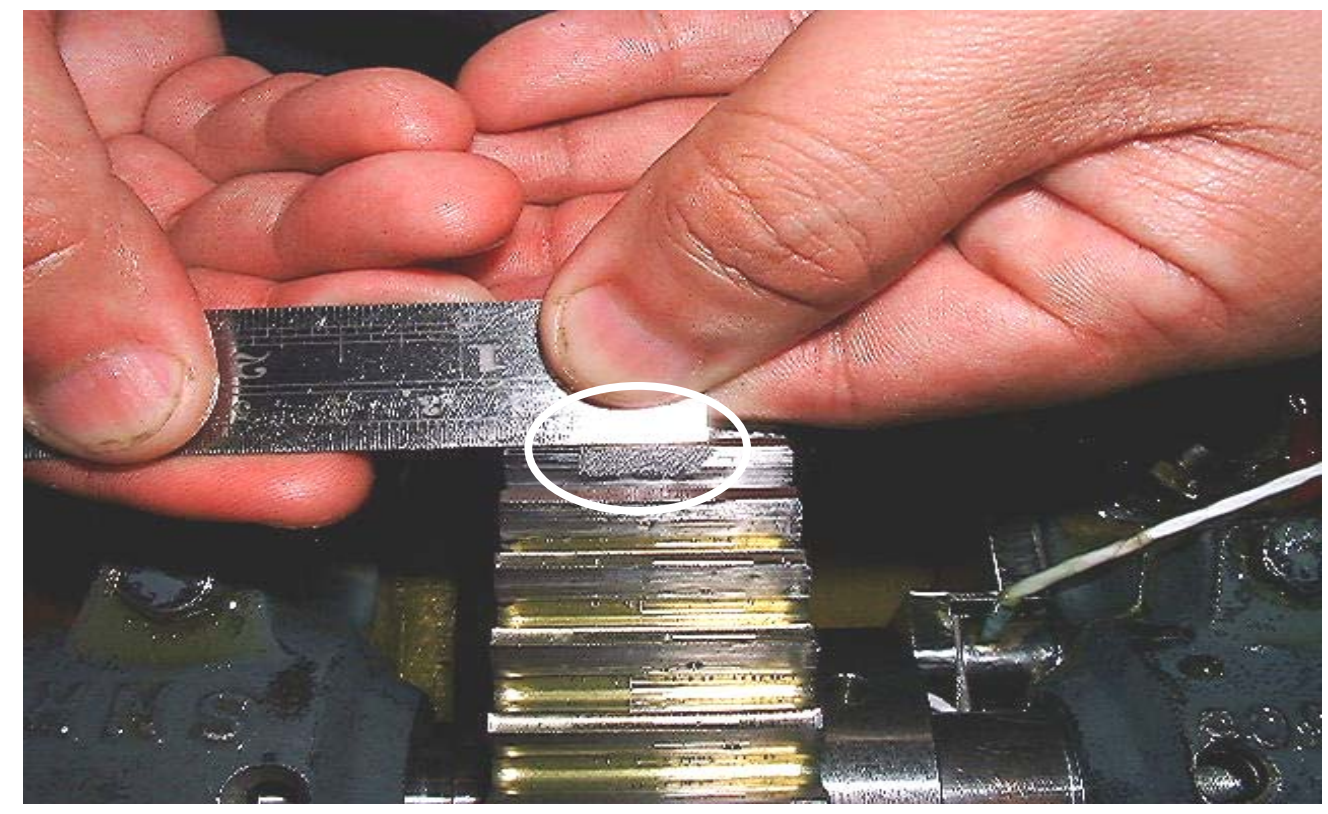

Figure 5 Seeded large addendum defect. 


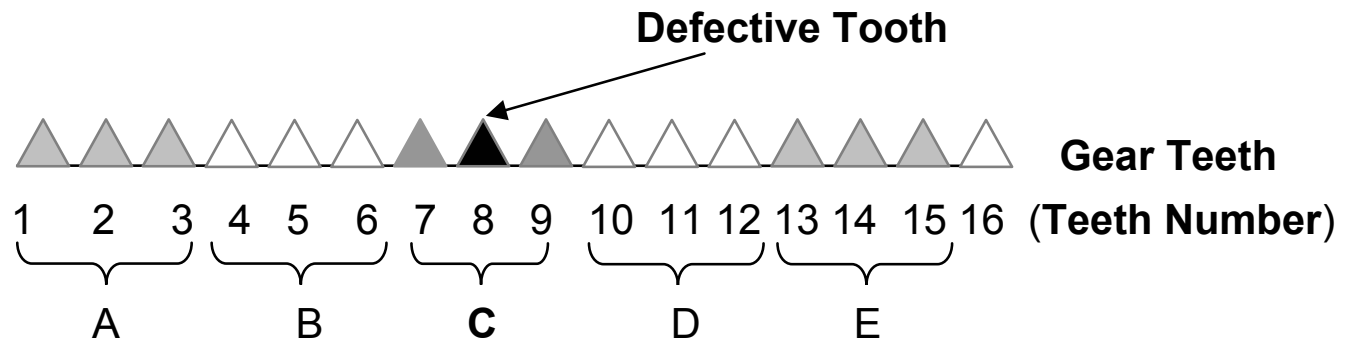

Figure 6 Sectioning of gear teeth for analysis, 16 teeth captured over 0.0256 seconds.

\section{Attenuation Test}

A $0.5 \mathrm{~mm}$ diameter and $3 \mathrm{~mm}$ length $2 \mathrm{H}$ lead pencil was broken at different positions in order to establish the attenuation of the AE signal. This technique is known as the Nielsen source test. Figure 7 presents the schematic diagram for the attenuation test displaying the different simulation positions and different interfaces the AE signatures would have to propagate across. Table 1 and figure 8 show the relative attenuation values. The reference signal employed for the attenuation calculations was the AE response from a lead break next to the $\mathrm{AE}$ sensor on the pinion gear. Five pencil breaks were acquired from each position and averaged.

The greatest attenuation of simulated AE signatures was observed on the bearing. This was expected due to the number of interfaces the AE signature would need to propagate across. The position of the balls in the loaded zone affects attenuation of the AE signal. If a ball is in the loaded zone while the $\mathrm{AE}$ waves were travelling through, better transmissibility can be expected. Relatively high attenuation was also observed for lead 
breaks on the wheel (big gear). This was expected as the wheel is furthest away from the sensor; however, the attenuation values of lead breaks on the pinion and shaft were similar. It was expected that the attenuation would be greater on the shaft due to the interface between the shaft and the pinion gear but this was not the case. This is attributed to experimental errors and the close proximity at both locations.

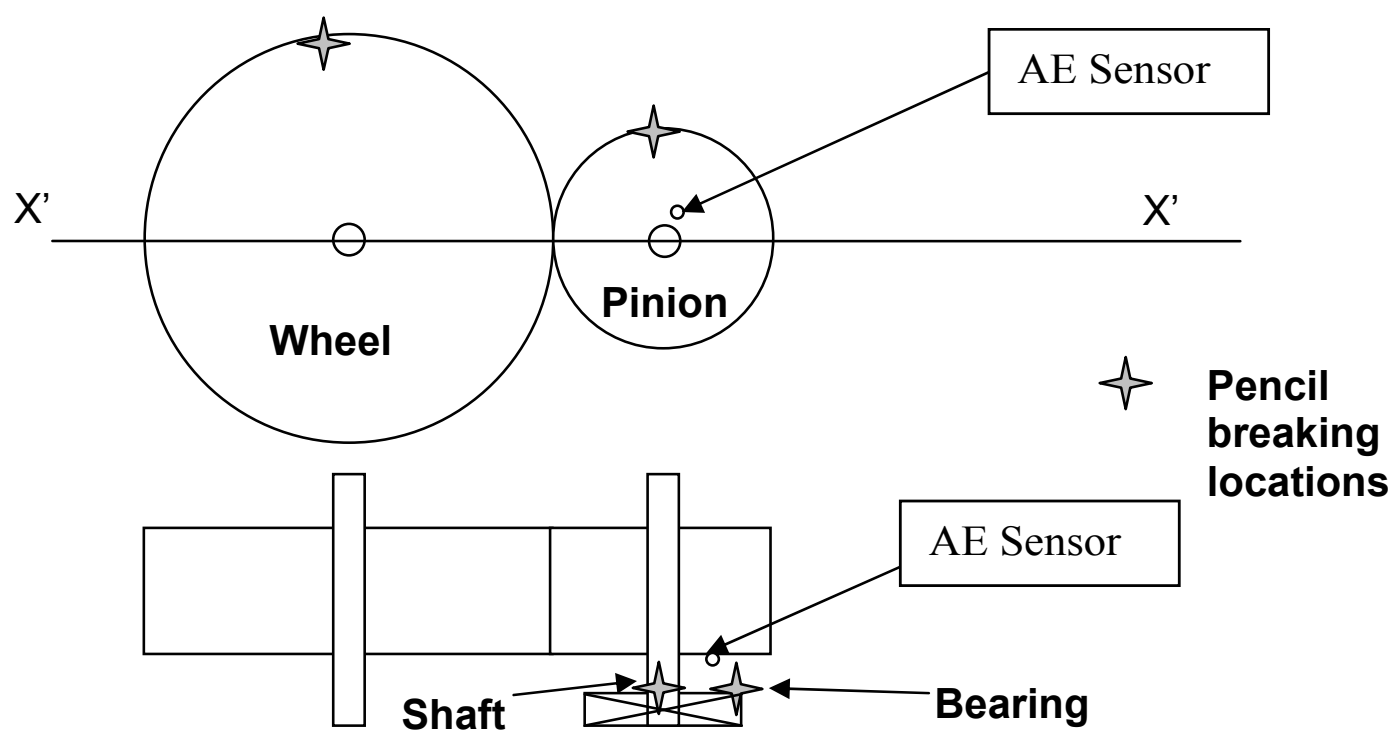

Figure 7 Schematic Diagram for the attenuation test displaying different interfaces 


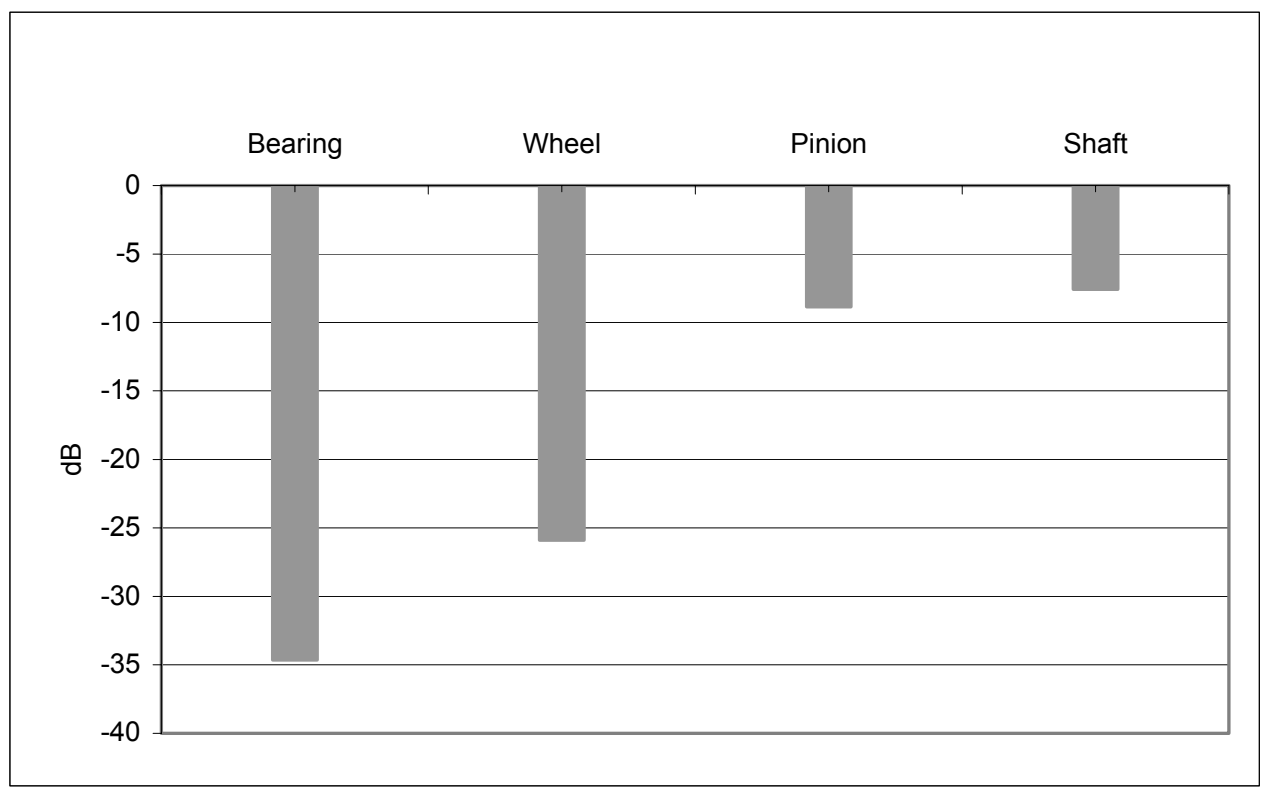

Figure 8 Relative attenuation values for sensor on the pinion.

Table $1 \quad$ Relative attenuation values

\begin{tabular}{|c|c|c|}
\hline Interface & Average Amplitude & Relative Attenuation (dB) \\
\hline Bearing & 0.093 & -34.64 \\
\hline Wheel & 0.257 & -25.90 \\
\hline Pinion & 1.829 & -8.86 \\
\hline Shaft & 2.120 & -7.58 \\
\hline & & \\
\hline Reference Position & 5.074 & 0 \\
\hline
\end{tabular}

\section{Results of operational background noise}

Figure 9 displays a typical AE signature with corresponding frequency spectrum associated with a defect free condition (operational noise). Figure 10 illustrates the time domain signatures for the load cases considered. It clearly shows 16 meshing teeth that 
included the defective tooth. This is the first known published document that presents the gear meshing $\mathrm{AE}$ transient response in the time domain. The gear mesh frequency can also be calculated from the time domain AE signal by inversing the periodic time between two subsequent $\mathrm{AE}$ bursts. The frequency range of the transient and continuous AE signals associated with these tests ranged from $25 \mathrm{kHz}$ to $350 \mathrm{kHz}$.

For analysis of AE data obtained from these experiments r.m.s values were calculated to provide a comparison to other published work but principally because of the simplicity and proven robustness of this parameter for machine health diagnosis.
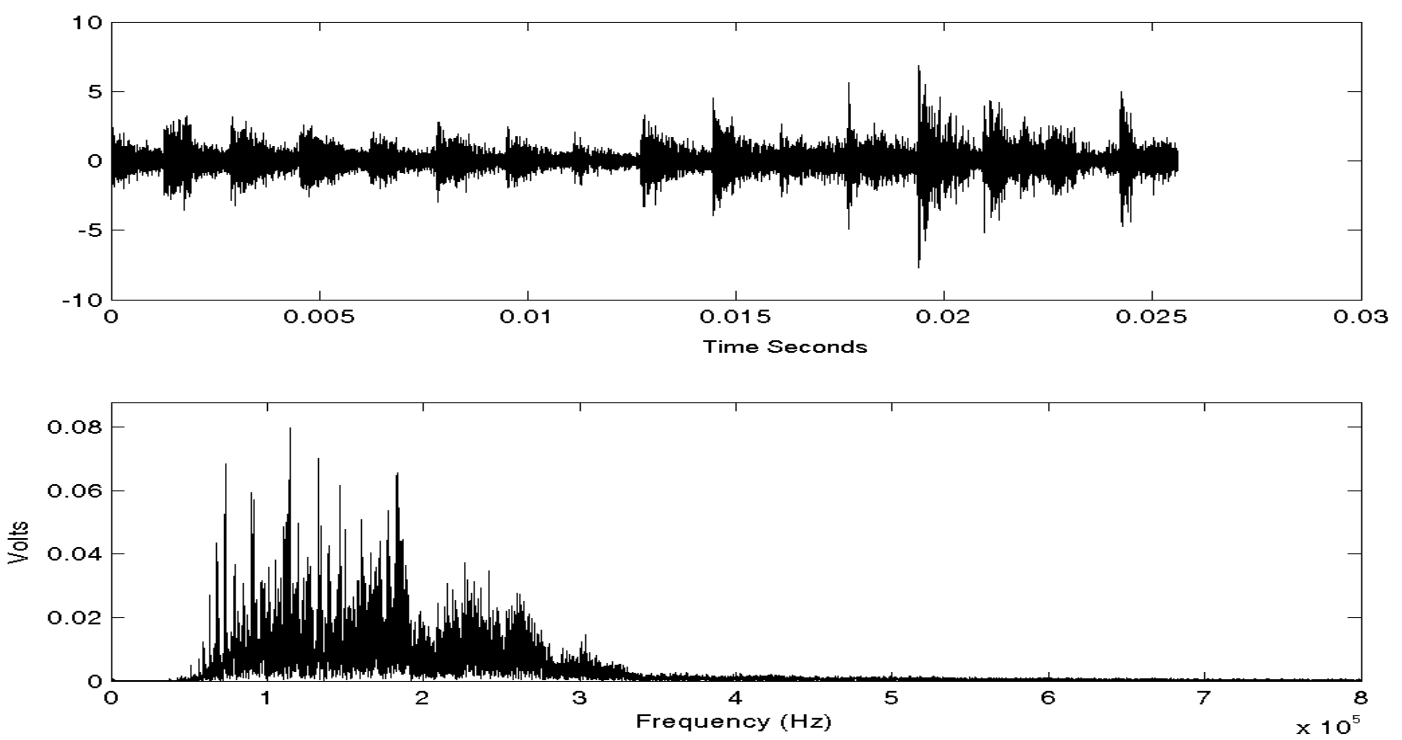

Figure 9 Time and frequency domain of an AE signature showing clearly the AE transient response associated with gear meshing of 16 teeth. 

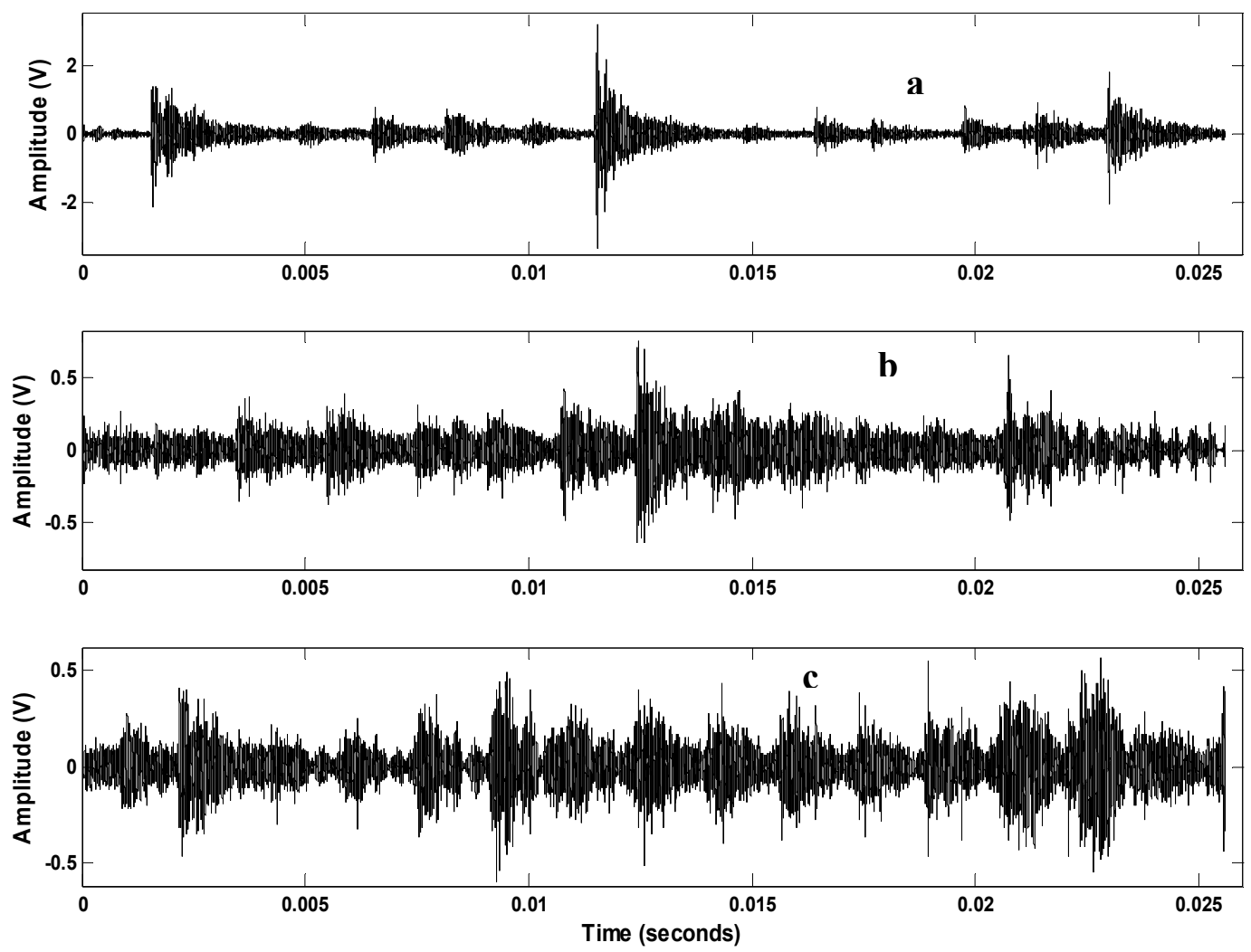

Figure 10 Raw AE signal for small pitch-line defect for (a) no load,

(b) $55 \mathrm{Nm}$ load and (c) $110 \mathrm{Nm}$ load.

\section{Results of defect simulations}

The recorded AE time waveform acquired for defect and defect free simulations were split into five different regions with each region representing 3-teeth, see figure 6 . The r.m.s. value of each region was computed and plotted against the three loading conditions. It was thought that this method of grouping the data would enhance the possibilities of detecting the seeded defect particularly as the defect has been seeded in the centre of the acquisition window. A total of 50 data sets, each equivalent to a time frame encompassing sixteen teeth, were acquired and averaged in each region. The 
averaging could be accomplished due to the optical triggering system employed ensuring that the acquisition system always started at the same position.

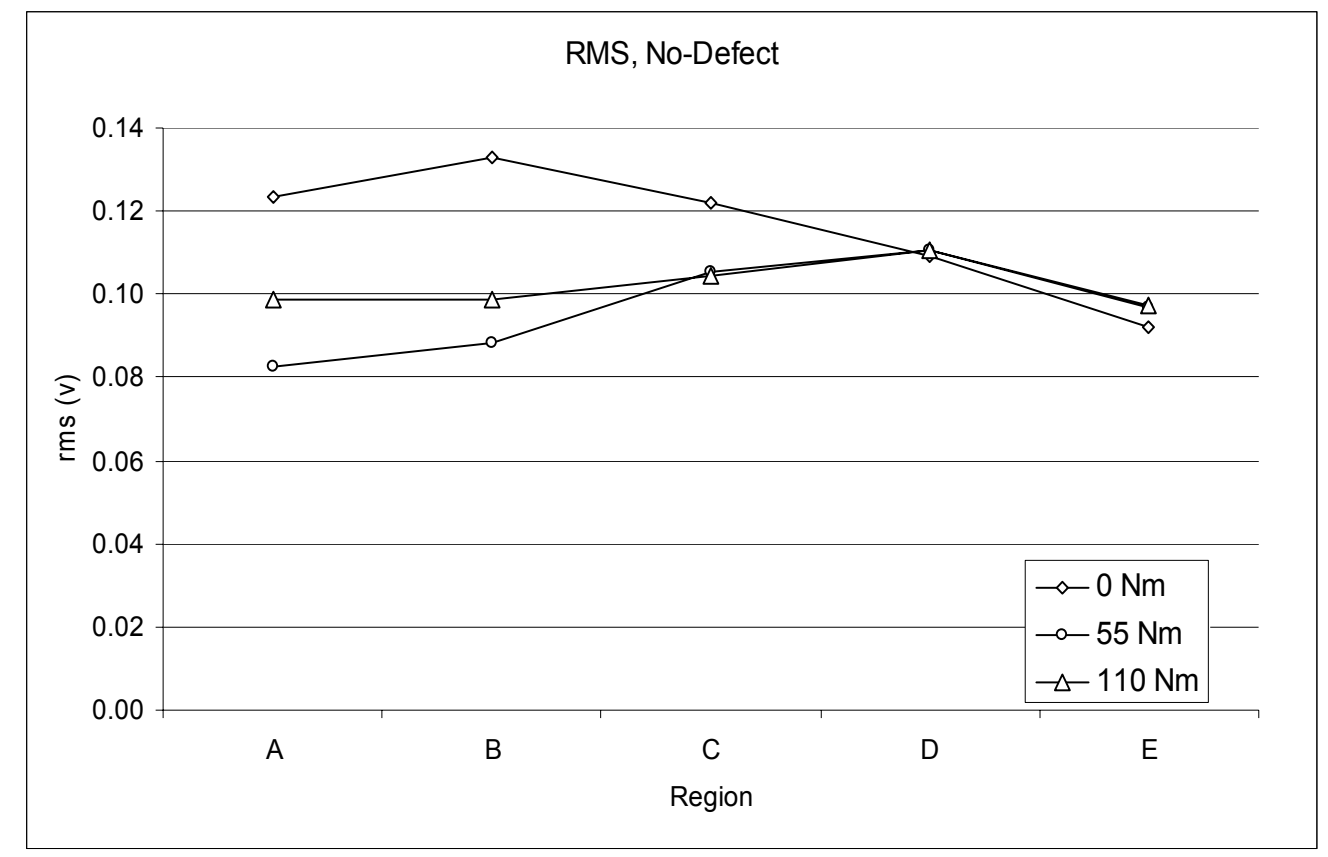

Figure 11 r.m.s. against load for defect free condition. (5 regions).

For the defect free simulation r.m.s values calculated showed no discernible trend for the three loading conditions, see figure. For the small pitch-line defect condition, the centre region $\mathrm{C}$, where the seeded defect was introduced, exhibited the highest r.m.s values (figure 12). However, similar observations were not present for the large addendum defect (figure 13). It was also noted that for the small defect condition only the r.m.s levels increased with increasing load. Furthermore, it was observed that r.m.s levels for the large fault condition were relatively lower than defect free and small defect conditions. The latter two had similar r.m.s values. These observations were rather puzzling, as the literature to date had advocated an increase in AE r.m.s/energy with defect size and load. 


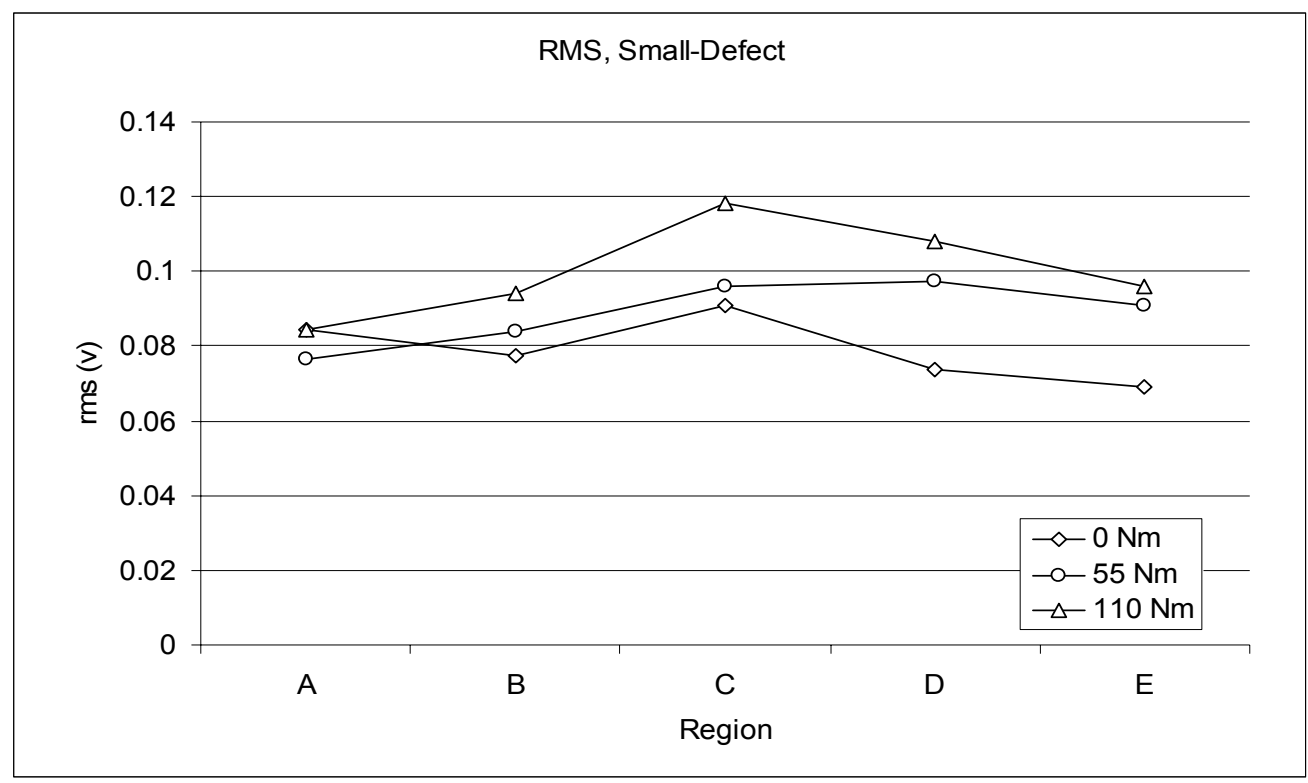

Figure 12 r.m.s. against load for small pitch-line defect condition. (5 regions)

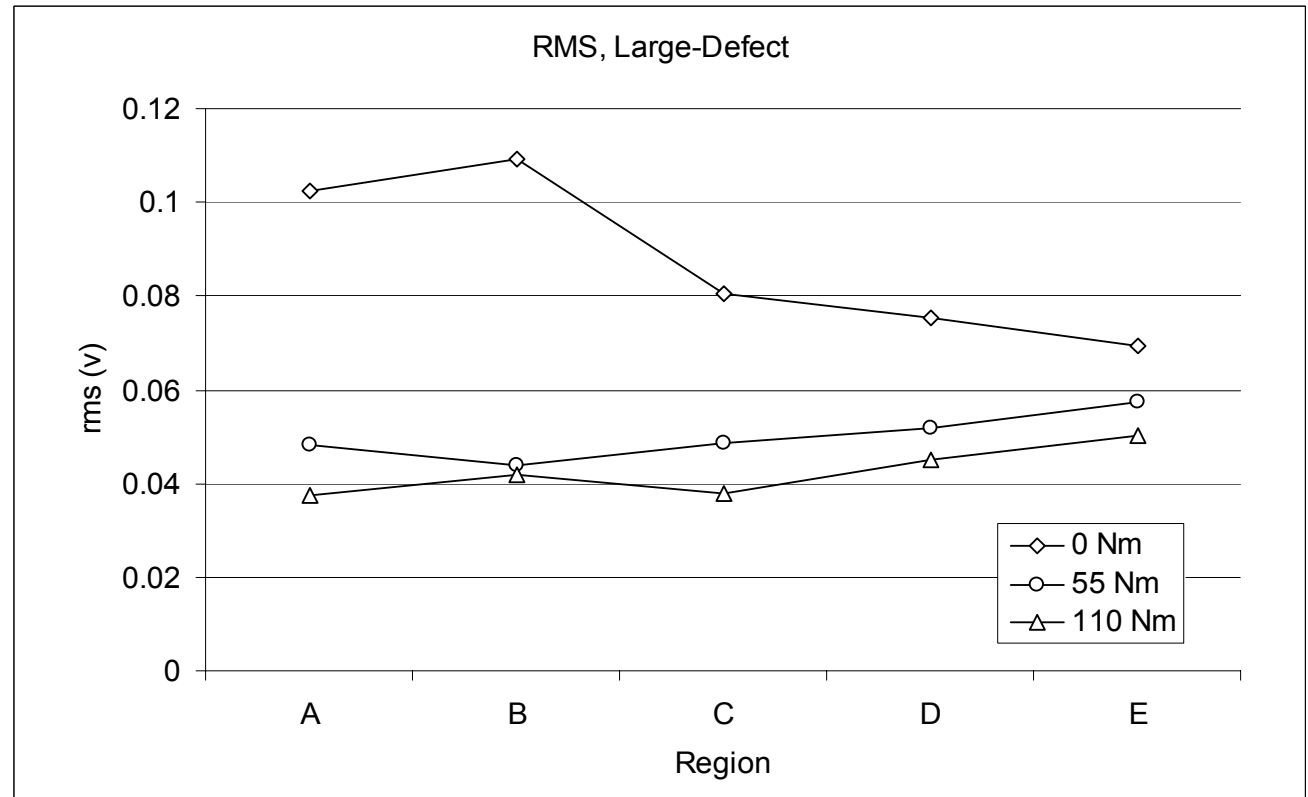

Figure 13 r.m.s against loads for large addendum defect condition. (5 regions) 
In order to confirm the authenticity of these results recorded AE data was split further into eight and sixteen different regions with each region representing 2-teeth and 1-tooth respectively. This was a similar procedure to that shown in figure 6 . The r.m.s. value of each region was computed and plotted against the three load conditions for the small defect condition, see figure 14 and 15 . The small defect condition was specially chosen as this showed the most promising results when the teeth were grouped in three's. From figure 14, it was observed that the maximum r.m.s. values did not occur at region D where the seeded defect was located based on a grouping of two teeth. From figure 15 similar observations were noted, the r.m.s. value at the seeded fault tooth, $\mathrm{H}$ (based on a single tooth demarcation), was not the highest value. The same observations were noted for the large defect condition. The inconsistency between the single tooth, 2-teeth and 3teeth analysis revealed that either the AE r.m.s or/and the potential for the AE technique for defect identification was inappropriate. The results would have been conclusive had the r.m.s. levels for the defective tooth been higher than other regions within the acquisition window.

The raw AE signal from small pitch-line defect is displayed in figure 10. This shows the non-consistent observation of $\mathrm{AE}$ bursts in relation to the defect position. The biggest burst of the AE signal did not always occur in the centre region of the window where the seed fault was located. Hence, it was not possible to detect the seeded defect using the AE r.m.s. This contradicts the work of a few researchers $[8,10,11]$ whom claimed AE energy, which is proportional to r.m.s, could clearly identify a simulated pit. Based on these observations the authors undertook further experiments in an attempt to understand the reasons for this, see section on discussions. 


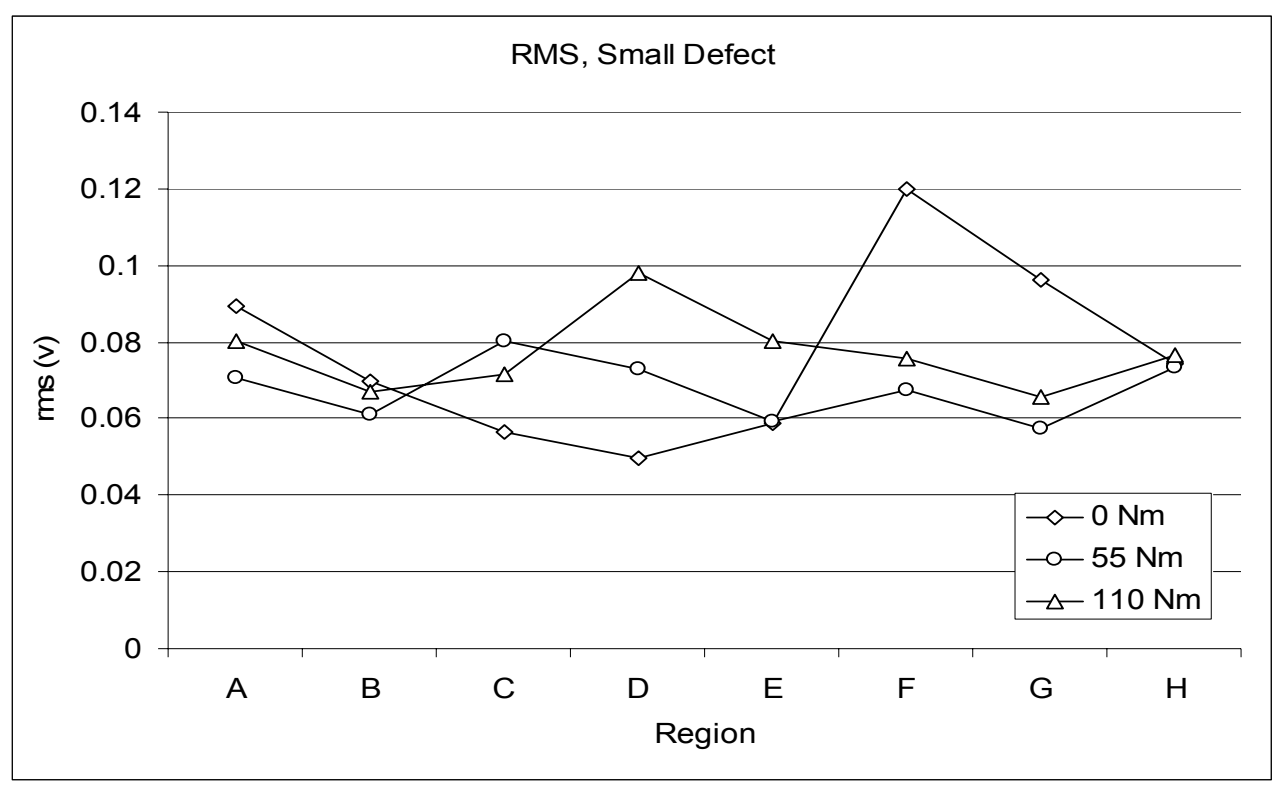

Figure 14 r.m.s against loads for small pitch-line defect condition. (8 regions)

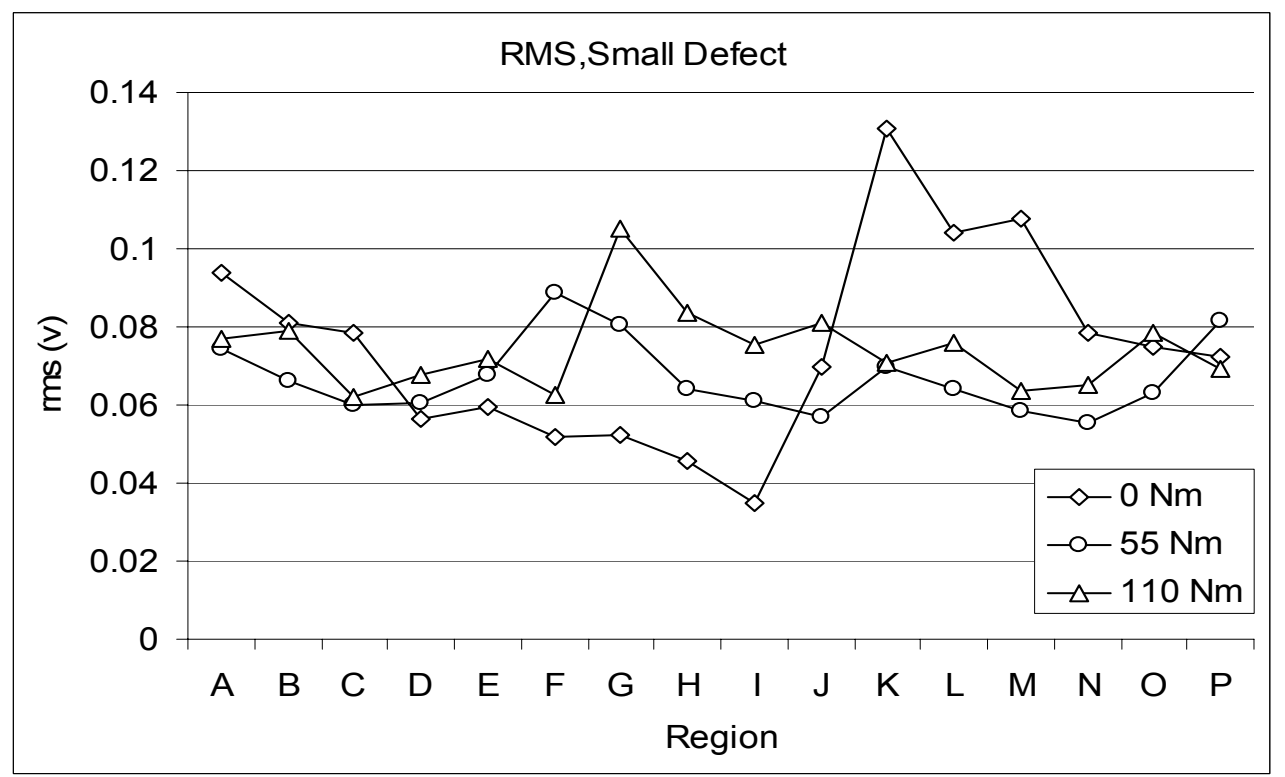

Figure 15 r.m.s against loads for small pitch-line defect condition. (16 regions) 


\section{AE Observations from the Bearing Housing}

The AE sensor on the pinion and bearing casing was synchronised and as such when the data acquisition system was triggered, both AE sensors captured data simultaneously.

During the test, it was noted that the AE bursts relating to the gear mesh, as detected on the sensor fixed onto the pinion, were also observed from the sensor on the bearing casing, see figure 16. However, continuous observations of the AE sensor on the bearing casing showed intermediate loss of the AE bursts associated with the gear mesh. The reason for this is attributed to the position of the bearing ball/roller elements during rotation. It is postulated that when the ball/roller is at bottom dead centre, i.e. directly in the load path, transmission of the AE bursts to the sensor on the bearing casing was achievable and only under this circumstance. As the relative attenuation ranged from $44 \mathrm{~dB}$ to $26 \mathrm{~dB}$ (depending on the particular gear mesh $\mathrm{AE}$ burst, see figure 16), in addition to the high probability of loss of transmission path through the bearing, see figure 17 , the authors see identifying gear defects from the bearing casing as fraught with difficulties, again contrary to other investigators $[6,8]$. 


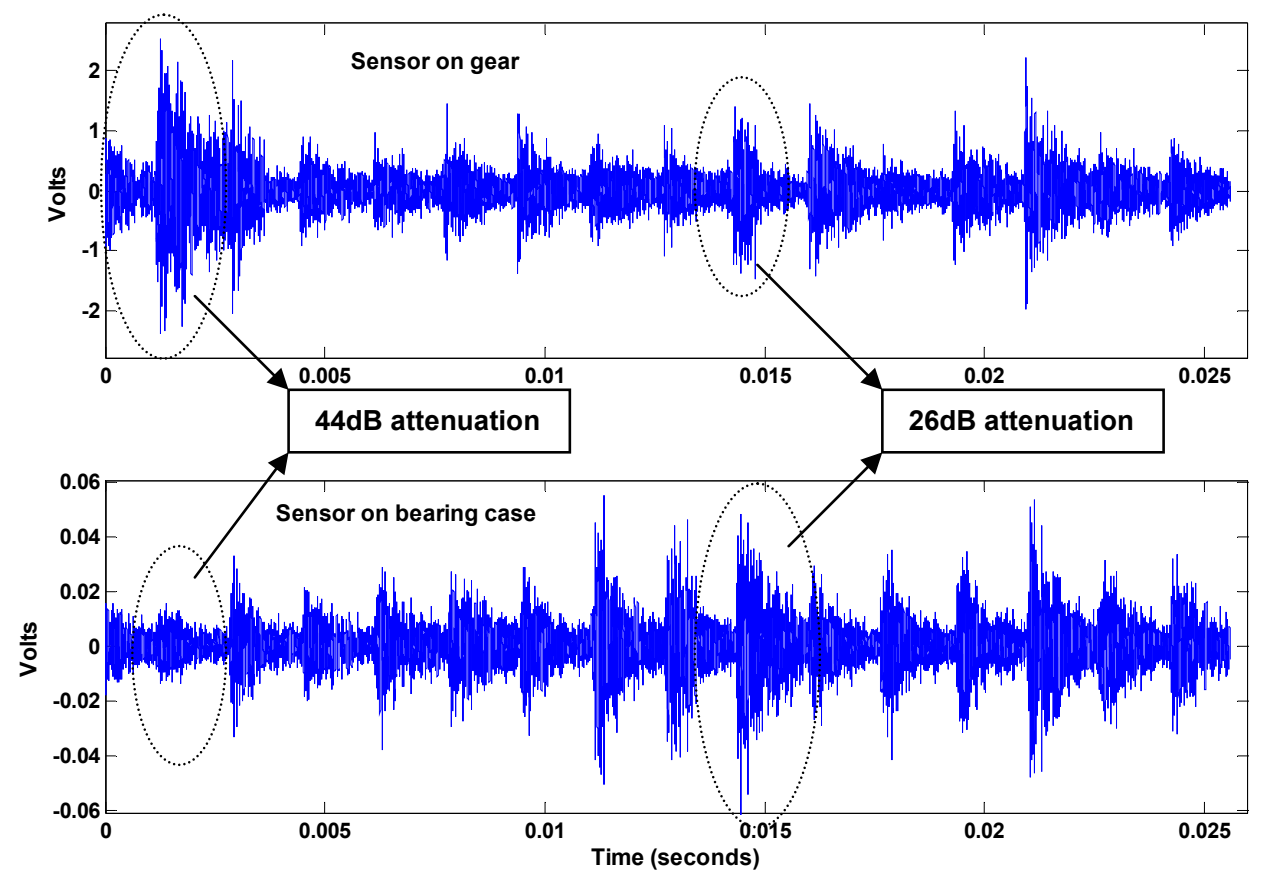

Figure 16 AE bursts detected on pinion sensor were observed on bearing casing sensor, load $55 \mathrm{Nm}$.

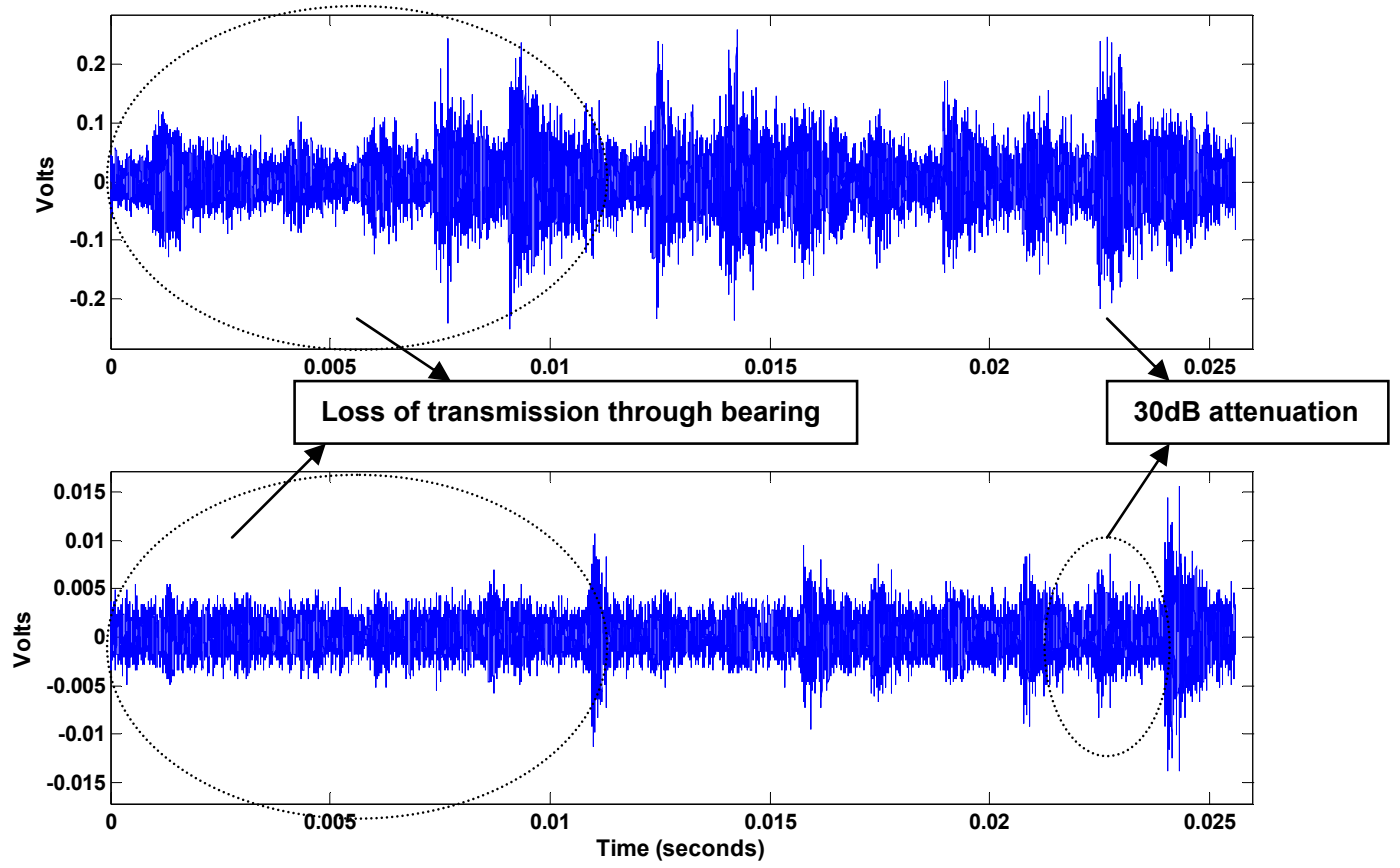

Figure 17 Loss of transmission path at particular gear mesh positions observed on bearing casing sensor, load $55 \mathrm{Nm}$. 


\section{Discussion}

The relationship between $\mathrm{AE}$ r.m.s and defect location presented thus far was considered unsatisfactory. This resulted in additional tests to explain the discrepancies, particularly as other authors had supported the applicability of these parameters to gear defect detection. These new tests were carried out using the same test set-up but with new gear sets. It was thought prudent to establish if the oil temperature had an influence on AE activity. For this investigation the AE r.m.s data were monitored and recorded continuously while oil temperature in the gearbox was also measured at fifteen minute intervals.

Continuous AE r.m.s values were calculated in real time by the Analog to Digital Converter (ADC) controlling software. This software employed a hardware accelerator to perform calculations in real time. The hardware accelerator takes each value from the $\mathrm{ADC}$ and squares it. These results are added into an accumulator for a programmable time interval set by the user, $100 \mathrm{~ms}$ in this instance. The accumulator is cleared at the start of the time interval, and the accumulator value will only be stored at the end of the time interval. The r.m.s is then calculated by taking the square root of the sum of the accumulated squared ADC readings. The time interval for acquisition was also set at $100 \mathrm{~ms}$.

These additional tests were run at three load conditions until the AE r.m.s. and oil temperatures stabilised. The tests were terminated when the AE parameters and oil 
temperatures had been stable for one hour. Stabilisation of the oil temperatures was achieved when the temperature remained within $0.2^{0} \mathrm{C}$ for the duration of one hour.

Figure 18 illustrates that the gearbox system only reached a stabilised temperature after at least 5 hours of continuous running. The starting point for all three test conditions investigated was dependent on the ambient temperature prior to testing. From figures 19 to 21 , it was noted that the AE r.m.s varied with time as the gear box reached a stabilised temperature. This implied that depending on what time the AE data was captured for a given speed and load condition, the variation in AE activity r.ms could be as much as $33 \%$. For these particular tests the point at which the data was captured is highlighted in figures 19 to 21 . Thus, the AE signals captured during seeded defect tests were 'snapshots' that are largely influenced by load, oil temperature and system dynamics. As 'snapshots' only provide information at an instant in time, the consistencies of the derived AE parameters will be subject to considerable variation. The influence of load and oil temperature on AE activity is directly linked to the oil film thickness between the meshing gears. The oil film thickness will influence the rate of wear and asperity deformation, both of which generate the AE activity. Therefore, it is important to determine and establish when the AE signal should be recorded for usage on comparative defect analysis.

The complications of the effect of oil temperature on AE activity have far reaching consequences, particularly as most of the published work to date has not taken cognisance of this effect. The authors of this paper believe it is fundamentally flawed to compare AE activity from defect free and simulated defect conditions under varying loads without accounting for the influence of oil temperature. The effect of oil 
temperature variation on the generation of $\mathrm{AE}$ activity is currently under investigation and will be the subject of future publication. It may be worth stating that the influence of oil temperature on $\mathrm{AE}$ activity for higher rotational speeds has shown far greater variations for similar load conditions than stated in this paper.

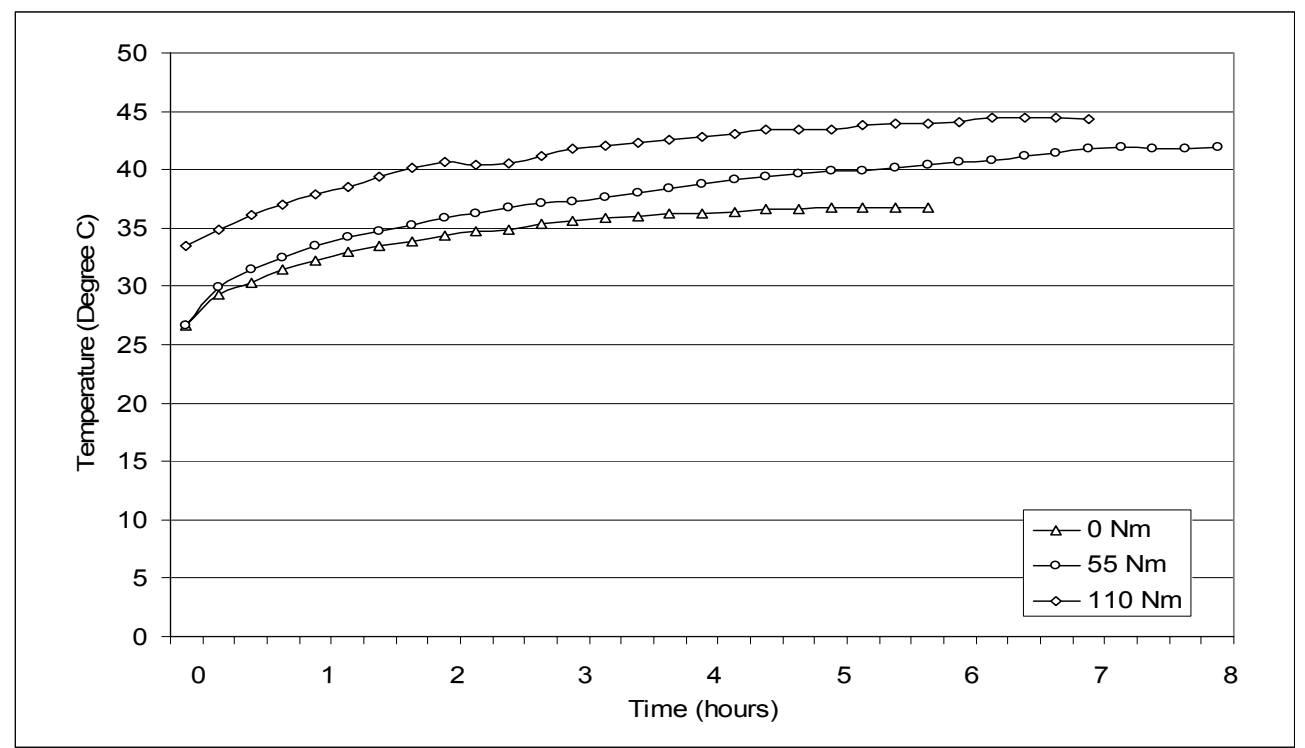

Figure 18 Oil temperatures monitoring with no-load, $55 \mathrm{Nm}$-load and $110 \mathrm{Nm}$ load conditions. 


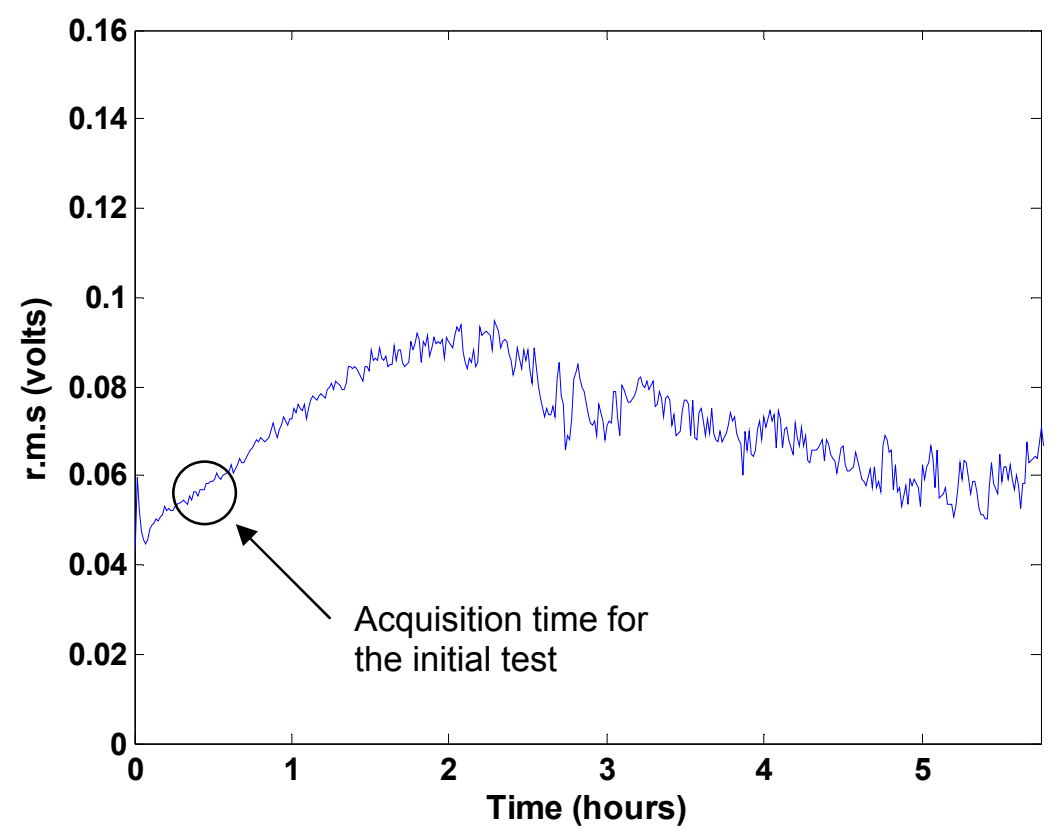

Figure 19 Continuous AE r.m.s values for no-load condition.

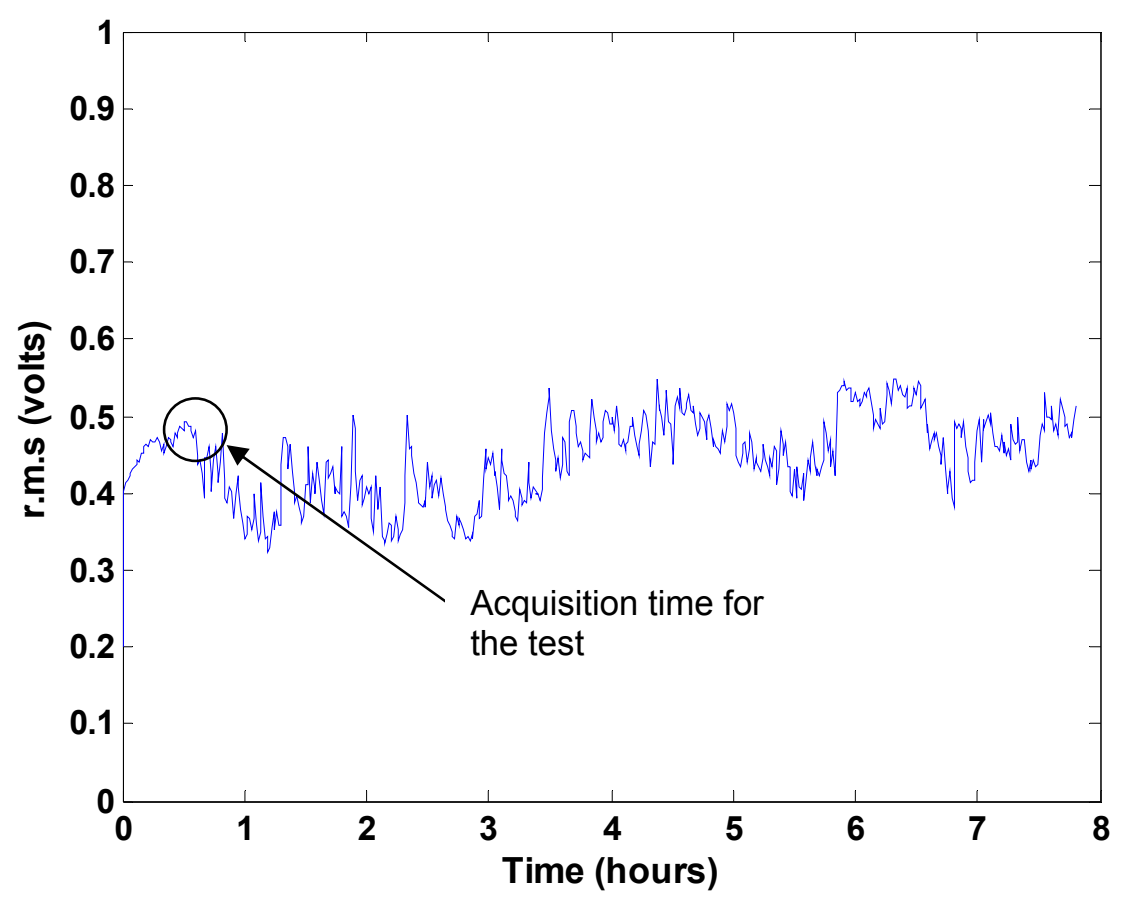

Figure 20 Continuous AE r.m.s values for $55 \mathrm{Nm}$ load condition. 


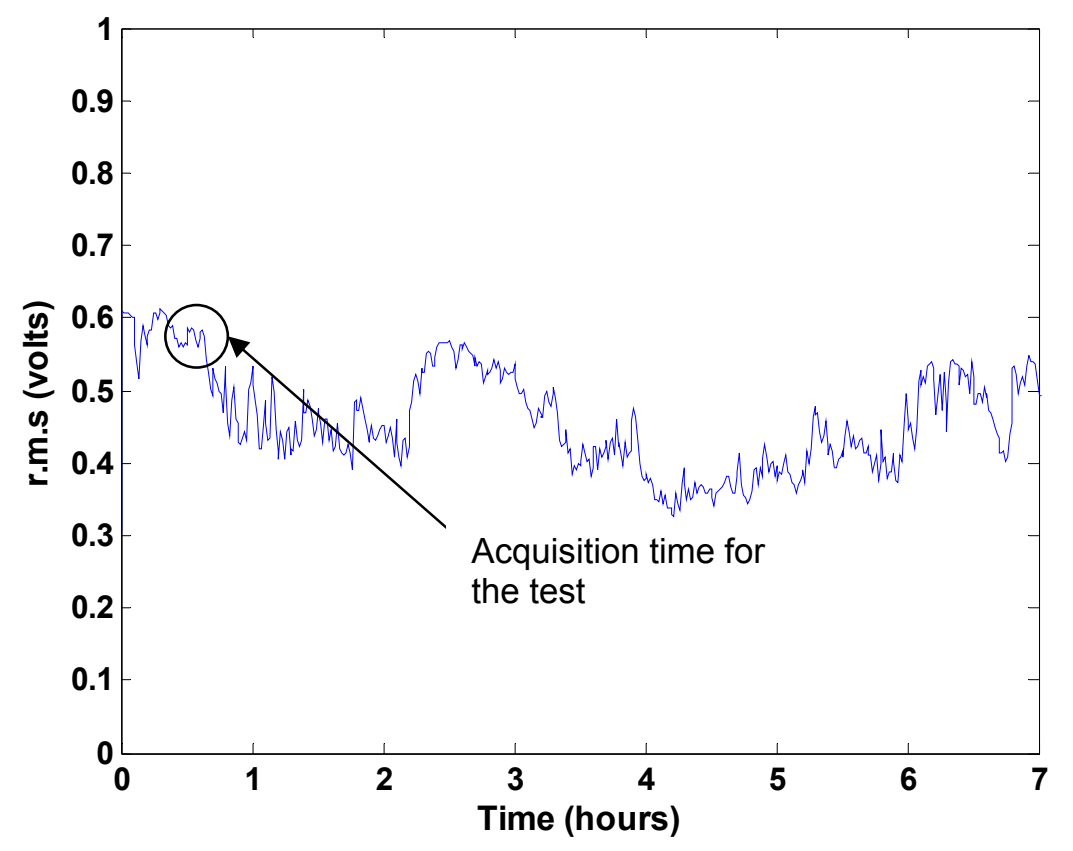

Figure 21 Continuous AE r.m.s values for $110 \mathrm{Nm}$ load condition.

Taking cosignance of the fact that AE activity is generated during the sliding and rolling of the gears, principally due to asperity contacts, the introduction of a seeded defect which removes surface material digresses from the basic source of $\mathrm{AE}$ generation. Therefore the authors argue that identification of seeded defects of this nature cannot be accomplished with the AE technique. This statement will hold true if the seeded defect involved the removal of material from the surface. However, other authors $[8,10,11]$ have claimed success and it is argued that the most likely reason for this is as follows: It is highly possible that in the process of material removal from the gear face 'mounds' or 'protrusions' will be formed at the boundaries of the seeded defect, see figure 22 . These are created due to the displacement of material from the region of material removal. The authors postulate that it is these 'protrusions' that were responsible for AE activity. However, this activity will only last until the 'protrusions' are flattened during the operation of the gear, see figure 23. In the latter instance, AE will be generated by 
asperity contacts. These postulations are based on the assumption that a suitable grade of lubricant is employed. On this basis the authors question the repeatability of seeded defect identification tests over a prolonged period using the AE technique.

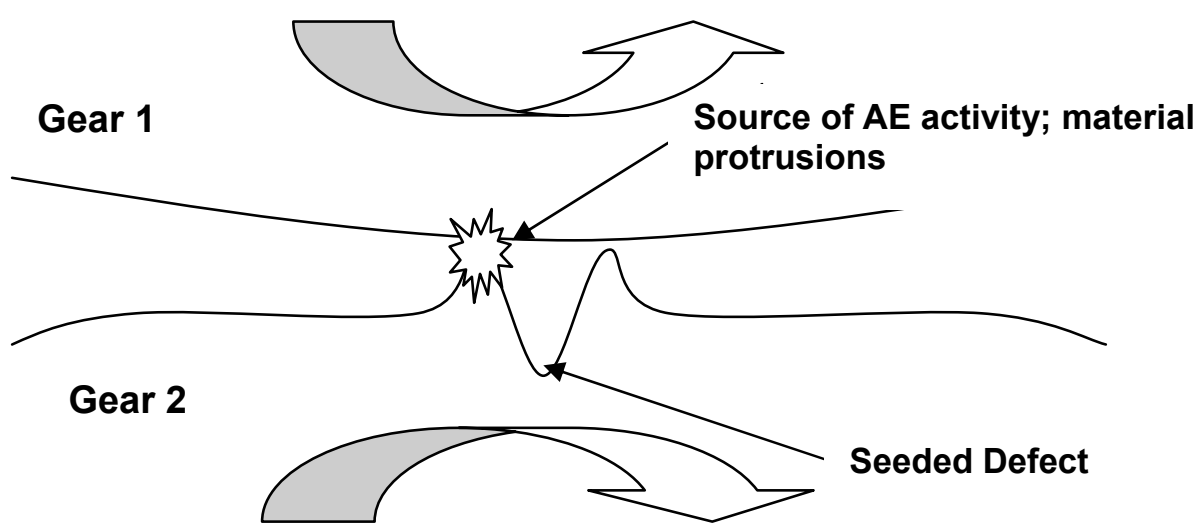

Figure 22 Mounds or Protrusions of the gear surfaces in contact during rotation

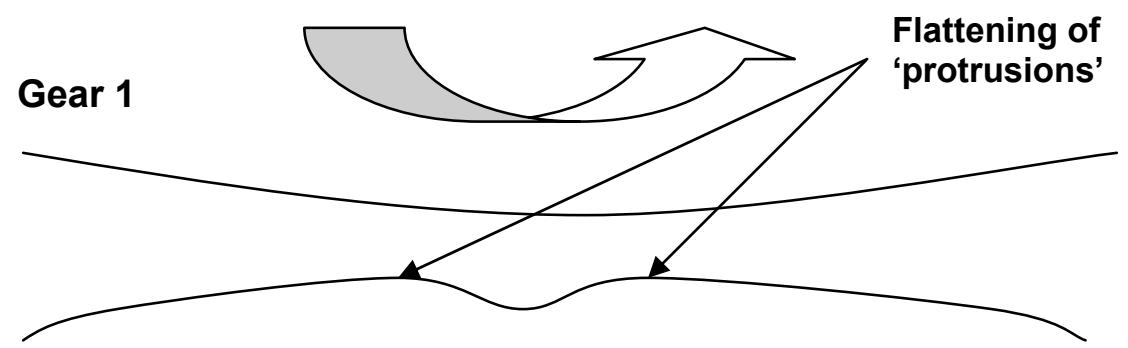

Gear 2

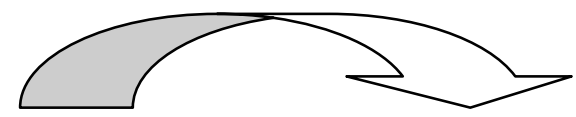

Figure $23 \quad$ Flattened protrusions of gear surfaces.

The pitting process of gears involves initiation of micro-cracks, crack growth and the removal of tiny particles from the gear surface, all of which emit AE activity. 
Furthermore, the removed wear particles or debris trapped between mating gear surfaces will create third-body abrasions. This condition will further enhance generation of AE signatures. For a better assessment on the detection capability of AE, it is recommended that experiments are undertaken in conditions, which allow natural pitting or wear rather than seeded defect test.

\section{Conclusion}

This paper has demonstrated that seeded gear defect detection with AE is fraught with difficulties and the reasons have been presented. This work is part of an ongoing program which aims to investigate some of the drawbacks detailed and establish if the technique is relatively robust for natural wear detection on gears.

\section{References}

1. Mba, D. and Bannister, R.H. (1999). Condition monitoring of low-speed rotating machinery using stress waves: Part1 and Part 2. Proc Inst Mech Engrs. 213(3), Part E, 153-185.

2. Holroyd, T. and Randall, N. (1992). The Use of Acoustic Emission for Machine Condition Monitoring. British Journal of Non-Destructive Testing. 35(2), 75.

3. Mba D. (2001). The detection of shaft-seal rubbing in large-scale turbines using acoustic emission. 14th International Congress on Condition Monitoring and Diagnostic Engineering Management (COMADEM'2001). Manchester, UK, 4-6 September 2001. 21-28, ISBN 0080440363. 
4. Mba, D. (2002). Applicability of acoustic emissions to monitoring the mechanical integrity of bolted structures in low speed rotating machinery: case study. $N D T$ and E International. 35(5), 293-300.

5. Mba, D., Cooke, A., Roby, D. and Hewitt, G. (2003). Opportunities offered by acoustic emission for shaft-seal rubbing in power generation turbines; a case study. International Conference on Condition Monitoring. Oxford, sponsored by the British Institute of NDT UK, 2-4 July 2003. 280-286, ISBN 1901892174.

6. Siores, E. and Negro, A.A. (1997). Condition Monitoring of a Gear Box Using Acoustic Emission Testing, Material Evaluation, ( 183-187.

7. Sentoku, H. (1998). AE in Tooth Surface Failure Process of Spur Gears, Journal of Acoustic Emission, 16(1-4), S19-S24.

8. Singh, A., Houser, D. R., and Vijayakar, S. (1996). Early Detection of Gear Pitting. Power Transmission and Gearing Conference, ASME. DE-Vol. 88, 673678.

9. Singh, A., Houser, D. R., and Vijayakar, S. (1999). Detecting Gear Tooth Breakage Using Acoustic Emission: A Feasibility and Sensor Placement Study, Journal of Mechanical Design, 121, 587-593.

10. Tandon, N. and Mata, S. (1999). Detection of Defects in Gears by Acoustic Emission Measurements. Journal of Acoustic Emission. 17(1-2), 23-27.

11. Toutountzakis, T. and Mba, D. (2003). Observation of Acoustic Emission Activity During Gear Defect Diagnosis. NDT and E International. 36(7), 471-477. 